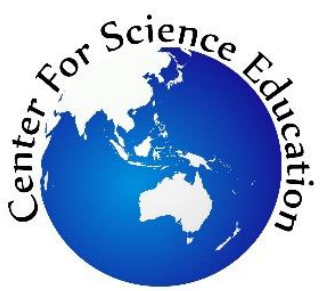

Tersedia online di EDUSAINS

Website: http://journal.uinjkt.ac.id/index.php/edusains

EDUSAINS, 12(2), 2020,214-222

Research Artikel

KEMAMPUAN LITERASI SAINS PADA SISWA SMA MENGGUNAKAN
PEMBELAJARAN KIMIA BERBASIS ETNOSAINS

\title{
SCIENTIFIC LITERACY OF SENIOR HIGH SCHOOL STUDENTS USING ETHNOSCIENCE BASED LEARNING CHEMISTRY
}

\author{
Teguh Wibowo $^{1^{*}}$, Ariyatun ${ }^{2}$ \\ ${ }^{1}$ Universitas Islam Negeri Walisongo, Indonesia \\ ${ }^{2}$ Universitas Negeri Semarang, Indonesia \\ *teguhwibowo@walisongo.ac.id
}

\begin{abstract}
Scientific literacy skills are needed to understand science issues, the risks, and benefits of science, and understand the nature of science, including its relationship to culture. This study aimed to determine students' scientific literacy in using ethnoscience-based learning-chemistry. The study Method used quasi-experimental by nonequivalent control group design. The subject was grade XI-MIPA of SMAN 1 Kendal. The data collection techniques are test instruments to know students' scientific literacy. The analysis data technique is descriptive and inferential statistical analysis (independent sample t-test and $N$-gain). The results showed that the ethnoscience based learning-chemistry could increase students' scientific literacy. The mean score of students' scientific literacy on experiment and control class was $72 \%$ (high category) and 65\% (medium category), and count -3,551 and table -1,995. N-gain score experiment class of 0,47 (medium) and control class of 0,28 (low). Ethnoscience-based chemistry learning can be used in chemistry learning to develop students' chemical literacy skills.
\end{abstract}

Keywords: chemistry learning; colloid; ethnoscience; local wisdom; scientific literacy

\begin{abstract}
Abstrak
Kemampuan literasi sains dibutuhkan untuk memahami isu-isu sains, resiko dan manfaat sains, serta untuk memahami sifat sains, termasuk hubungannya dengan budaya. Penelitian ini bertujuan mengetahui kemampuan literasi sains siswa melalui pembelajaran kimia berbasis etnosains. Metode penelitian yang digunakan adalah quasi experimental dengan desain nonequivalent control group design. Subjek penelitian ini adalah siswa kelas XI MIPA SMAN 1 Kendal. Teknik pengumpulan data berupa tes untuk mengetahui kemampuan literasi siswa. Teknik analisis data menggunakan analisis deskriptif dan statistik inferensial (independent sample t-test dan uji N-gain). Berdasarkan hasil penelitian tersebut dapat dilihat bahwa pembelajaran kimia berbasis etnosains dapat meningkatkan kemampuan literasi sains siswa. Rerata skor kompetensi literasi sains siswa kelas eksperimen dan kontrol secara berturut-turut mendapat $72 \%$ dengan kategori tinggi dan $65 \%$ dengan kategori sedang, serta $t_{\text {hitung }}$ sebesar $-3,551$, dan $t_{\text {tabel }}$ nya 1,995. Adapun nilai N-gain pada kelas eksperimen adalah 0,47 (kategori sedang) sedangkan kelas kontrol adalah 0,28 (kategori rendah). Pembelajaran kimia berbasis etnosains dapat digunakan dalam pembelajaran kimia untuk mengembangkan kemampuan literasi kimia siswa.
\end{abstract}

Kata Kunci: etnosains; kearifan lokal; koloid; literasi sains; pembelajaran kimia

Permalink/DOI: http:// doi.org/10.15408/es.v12i2.16382 


\section{PENDAHULUAN}

Pada abad ke-21 mengalami perkembangan yang sangat cepat, hal ini meliputi di berbagai sektor kehidupan antara lain sektor teknologi, informasi, komunikasi, ekonomi dan lainnya. Perkembangan itu harus diimbangi dengan penguasaan kompetensi dalam kaitannya dengan keterampilan berpikir abad ke-21 yang mencakup berpikir kritis, kreativitas dan inovasi, kolaborasi, komunikasi dan literasi (Redhana, 2018). Menurut Toharudin \& Rustaman (2011) keterampilan abad ke-21 ada empat cakupan pokok yaitu literasi pada era digitalisasi, berpikir secara inventif, komunikasi yang yang baik, benar dan efektif, dan produktivitas kehidupan yang tinggi. Generasi yang kompetitif diperlukan dalam penguasaan ilmu pengetahuan alam dan teknologi yang mengacu pada kemampuan literasi sains (Setiawan, et al, 2017). Oleh karena itu beberapa negara menjadikan literasi sains merupakan tujuan utama dalam pendidikan sains (Sumarni, et al, 2017).

Kemampuan literasi sains dibutuhkan untuk memahami isu-isu sains, resiko dan manfaat sains, serta untuk memahami sifat sains, termasuk hubungannya dengan budaya (Fasasi, 2017), sehingga setiap orang harus menguasainya untuk mengikuti perkembangan sains dan teknologi semakin pesat (McCright, 2012). Kemampuan literasi sains digunakan seseorang untuk memahami kondisi lingkungan dan permasalahanpermasalahan sosial kemasyarakatan yang dihadapi oleh masyarakat pada era modern ini, terutama yang mengandalkan peranan perkembangan ilmu pengetahun dan teknologi (Turiman, et al, 2012). Seseorang yang mempunyai kemampuan literasi sains dapat mengaplikasikan konsep sains dalam interaksinya dengan lingkungan serta menggunakan proses sains dalam menyelesaikan masalah dan mengambil keputusan dalam kehidupan sehari-hari berdasarkan bukti-bukti ilmiah (Handayani, et al, 2018).

Survei yang diselenggarakan PISA (Program for International Student Assessment), bahwa rerata skor kemampuan literasi sains di Indonesia pada tahun 2018 sebesar 396, dengan menempatkan Indonesia berada pada peringkat ke-74 dari 79 negara peserta. Indonesia hanya berada di atas
Maroko, Lebanon, Kosovo, Republik Dominika dan Filipina. Berarti pada tahun 2018 mengalami penurunan skor sebesar 7 dari tahun 2015. Berdasarkan data yang diperoleh sekitar $40 \%$ siswa di Indonesia mencapai Level 2 atau siswa Indonesia baru pada kemampuan mengenali penjelasan yang benar untuk fenomena ilmiah yang sudah dikenal dan dapat menggunakan pengetahuan tersebut untuk mengidentifikasi, dalam kasus-kasus sederhana (OECD, 2019).

Hal tersebut juga diperkuat berdasarkan penelitian pendahuluan di SMAN 1 Kendal bahwa kemampuan literasi sains pada mata pelajaran kimia siswa kota Kendal masih rendah. Kimia cenderung dipelajari sebagai suatu hasil akhir, konsep, teori dan hukum. Rata-rata literasi sains siswa pada sistem koloid hanya berada pada kemampuan secara konten dalam mengenal beberapa fenomena dasar dan siswa masih belum mampu untuk mengomunikasikan dan menghubungkan kemampuan tersebut dengan berbagai hal terkait sains, apalagi mengaplikasikan konsep-konsep kimia yang abstrak dan kompleks.

Rendahnya kemampuan literasi sains ini dipengaruhi oleh beberapa faktor diantaranya yaitu kurikulum pendidikan, metode dan model pembelajaran, sarana dan prasarana sekolah. Faktor minat, motivasi, sikap, keyakinan, dan kepercayaan diri siswa berpengaruh terhadap ilmu pengetahuan dan teknologi, serta komponen-komponen afektif juga mempunyai peranan sangat penting pada pengambilan keputusan siswa dalam memperoleh pengetahuan tersebut (Chonkaew, et al, 2016). Proses pembelajaran kimia yang berlangsung, guru kurang menekankan literasi sains siswa. suswa masih mengalami kesulitan untuk menerapkan konsep-konsep tersebut pada aktivitas harian untuk menyelesaikan permasalahan yang mereka alami. Siswa kurang mampu menguasai teori-teori, namun juga mempunyai kemauan dan mampu menerapkan pada aktivitas sosial.

Fenomena yang menunjukkan literasi sains siswa Indonesia rendah, misalnya: ketika hujan dengan kilat, mereka biasanya merasa aman untuk berlindung di bawah pohon, atau proses pemasakan buah menggunakan karbit, mereka masih mengganggap kalau itu ada suatu kebetulan (Hadi 
\& Ahied, 2017). Untuk itu perlu adanya pembelajaran kimia yang mampu meningkatkan kemampuan literasi sains siswa, terutama pada aspek kimia. Salah satunya adalah mengintegrasikan pembelajaran kimia yang relevan dengan kearifan lokal daerah Kendal. Materi pada pembelajaran kimia banyak diterapkan dan digunakan untuk berlangsungnya kehidupan manusia dan peranannya sangat dekat dengan aktivitas sehari-hari sehingga pembelajaran di sekolah seharusnya dapat melibatkan aplikasi materi ini dalam kehidupan nyata misalnya melalui pembelajaran proyek terintegrasi budaya lokal (etnosains).

Kualitas pembelajaran dapat dilaksakan dengan mengkaitkan budaya lokal ke dalam pembelajaran sains (etnosains) (Suardana, 2013). Budaya lokal dapat bermanfaat sebagai stimulus belajar untuk memberikan motivasi dan membantu siswa dalam mengontruksi pengetahuan (Sumarni, 2018). Pentingnya pengintegrasian budaya dalam pembelajaran sains (etnosains) juga disampaikan oleh Nieto \& Ling (2010), bahwa menghubungkan budaya dalam berbagai sektor menjadi penentu kebermaknaan pelayanan profesional, termasuk juga pelayanan pendidikan, maka guru harus mampu mengangkat unsur-unsur budaya untuk diakomodasi dalam pembelajaran. Pentingnya pengintegrasian budaya dalam pembelajaran sains sesuai dengan teori kontruktivisme sosial menjelaskan pentingnya pengintegrasian kompetensi budaya pada pendidikan (Mussana, 2012). Teori ini menitikberatkan pada konsep sosiokultural, yaitu cakupan sosial dan berhubungan dengan pihak lain pada proses pembelajaran. Pembelajaran tidak sekedar dilakukan ketika siswa menyelesaikan tugas yang belum pernah di sekolah namun tugas tersebut dapat dikerjakan dengan hasil maksimal. Oleh karena itu, siswa perlu memperoleh pengalaman dalam proses pembelajarannya yang terintegrasi budaya.

Alasan pemilihan etnosains dalam pemilihan pendekatan pembelajaran adalah karena etnosains mampu meningkatkan kemampuan berpikir kritis dan sikap siswa berbasis kearifan lokal, sehingga menghasilkan kesinambungan antara pengetahuan kimia melalui pengintegrasian sikap ilmiah dan karakter yang berbasis nilai kearifan lokal (Sudarmin, et al, 2014). Perlakuan ini akan menjadikan konsep pendidikan kimia akan mempunyai manfaat untuk siswa, mayarakat dan Bangsa. Hal ini selaras dengan prinsip reformasi pendidikan sains saat ini yang menitikberatkan pada peranan pendidikan sains untuk memberikan manfaat untuk meningkatkan social responsible (Kun, 2013).

Pembelajaran kimia berbasis etnosains didasarkan pada pengakuan budaya lokal yang menjadi bagian dasar bagi pendidikan sebagai wadah untuk mengekpresikan dan mengkomunikasikan suatu ide dan perkembangan ilmu pengetahuan (Parmin, et al, 2017). Etnosains merupakah sebuah kajian yang memberikan gagasan tentang sistem pengetahuan yang dikelola dari budaya dan fenomena terkait dengan alam semesta yang ada di masyarakat (Setiawan, et al, 2017). Pembelajaran kimia dengan berorientasi pada kearifan lokal budaya daerah setempat dapat diintegrasikan secara tepat dan efektif. Pengintegrasian pada proses pembelajaran mempunyai harapan supaya siswa mampu menerapkan konsep sains, mendesiminasikan hasil diskusi dan menghubungkan berbagai materi sains dengan sains asli masyarakat, sehingga literasi sains siswa meningkat (Suastra, 2013).

Berdasarkan permasalahan tersebut, kepemilikan budaya lokal di Indonesia sebagai identitas suatu bangsa perlu ditingkatkan sebagai sumber pembelajaran dalam pendidikan sains. Pendidikan sains yang memperhitungkan budaya lokal, kebijaksanaan, identitas nasional, karakter dan kebiasaan budaya lokal adalah satu hal yang perlu dipertimbangkan dalam pengembangan kurikulum 2013 saat ini (Sudarmin, et al, 2017). Oleh karena ini, pada penelitian ini bertujuan untuk dapat meningkatkan kemampuan literasi sains siswa melalui pembelajaran kimia berbasis etnosains.

\section{METODE}

Jenis penelitian yang digunakan adalah penelitian kuantitatif dengan metode penelitian ini 
adalah quasi experimental. Variabel yang menjadi pokok bahasan adalah model pembelajaran berbasis etnosains. Penelitian ini menggunakan desain eksperimen nonequivalent control group design.

Populasi pada penelitian ini adalah seluruh siswa kelas XI IPA di SMAN 1 Kendal. Pemilihan subjek ini karena SMAN 1 Kendal mempunyai entitas yang berbeda dengan sekolah lain di Kota Kendal. SMAN 1 Kendal merupakan satu-satunya SMA di Kota Kendal yang sudah menerapkan kurikulum menggunakan Sistem Kredit Semester (SKS). Sampel dari penelitian ini diambil sebanyak 2 kelas dengan menggunakan Cluster Random Sampling dengan asumsi semua kelas memiliki karakteristik yang homogen/ relatif homogen (tidak ada kelas unggulan).

Intrumen pada penelitian ini berupa tes untuk memperoleh informasi terkait keefektifan pembelajaran kimia berbasis etnosains. Sebelum digunakan untuk mengukur keefektifan pembelajaran kimi berbasis etnosains, soal tes diujicobakan untuk mengetahui validitas (korelasi point biserial), reliabilitas (Alpha Cronbach), tingkat kesukaran dan daya beda soal. Berdasarkan Tes ini akan membantu peneliti untuk melihat sejauh mana pembelajaran kimia berbasis etnosains yang diterapkan memberikan dampak positif dalam kompetensi literasi sains siswa. Tes ini dilakukan pada pretest dan posttest pada kedua kelompok, yaitu kelompok yang menggunakan pembelajaran kimia berbasis etnosains dan kelompok yang menggunakan model pembelajaran kooperatif standar. Setelah dilakukan pretest dan posttest, akan bisa dilihat perbedaan kompetensi sains kimia diantara kedua kelompok tersebut. Kemudian uji hipotesis dilakukan dengan uji Wilcoxon dengan taraf signifikansi 0,05 dan mengetahui besarnya peningkatan kompetensi literasi sains siswa yang diperoleh dari perhitungan rumus $\mathrm{N}$-gain (g) yaitu dengan membandingkan skor pretest dan posttest.

\section{HASIL DAN PEMBAHASAN}

Permasalahan rendahnya kemampuan literasi sains di Indonesia yang masih rendah diharapkan dapat ditingkatkan dengan berbagai penerapan model pembelajaran yang tepat. Penelitian ini bertujuan untuk menganalisis kemampuan literasi sains (dalam hal ini adalah literasi kimia) siswa melalui pembelajaran kimia berbasis etnosains. Kemampuan literasi sains siswa pada penelitian ini diukur dengan menggunakan tes kompetensi literasi sains materi koloid yang telah diuji validitas, reliabilitas, tingkat kesukaran dan daya beda. Berdasarkan 30 butir soal yang telah diujicobakan mendapatkan hasil bahwa 20 butir soal valid dan 10 butir soal tidak valid dengan nilai realibilitas $r=$ 0,88 (realibilitas tinggi).

Kompetensi literasi sains yang diukur dalam penelitian ini meliputi kompetensi menjelaskan fenomena ilmiah, mengevaluasi dan merancang penyelidikan ilmiah serta menafsirkan data dan bukti ilmiah. Tes kompetensi literasi sains dilakukan di kelas XI MIPA SMA N 1 Kendal. Berdasarkan analisis uji homogenitas terhadap nilai raport semester 1, dari kelas XI MIPA SMA N 1 Kendal diperoleh nilai signifikansi 0,169, menunjukkan bahwa kelas yang digunakan pada penelitian ini homogen atau berasal dari populasi yang sama.

Tes kompetensi literasi sains terdiri dari 20 butir soal pilihan ganda yang mencakup tiga aspek kompetensi literasi sains. Setiap aspek kompetensi literasi sains memiliki indikator yang berbeda-beda. Ketercapaian kemampuan literasi sains secara keseluruhan diperoleh dengan menghitung rata-rata persentase siswa yang menjawab benar pada tiaptiap butir soal.

Perolehan data hasil penelitian terkait kemampuan literasi sains pada masing-masing indikator kompetensi literasi sains diperoleh dengan menghitung persentase ketercapaian hasil tes tiap indikator kemudian membandingkan nilai yang diperoleh masing-masing siswa dengan nilai maksimal dan mencari nilai rata-rata ketercapaian kemampuan kompetensi literasi sains untuk masing-masing indikator. Hasil tes kompetensi literasi sains kemudian dianalisis pada setiap aspek literasi sains. Hasil analisis rerata kompetensi literasi sains siswa pada setiap aspek kompetensi dirangkum secara ringkas dan disajikan pada Gambar 1. 


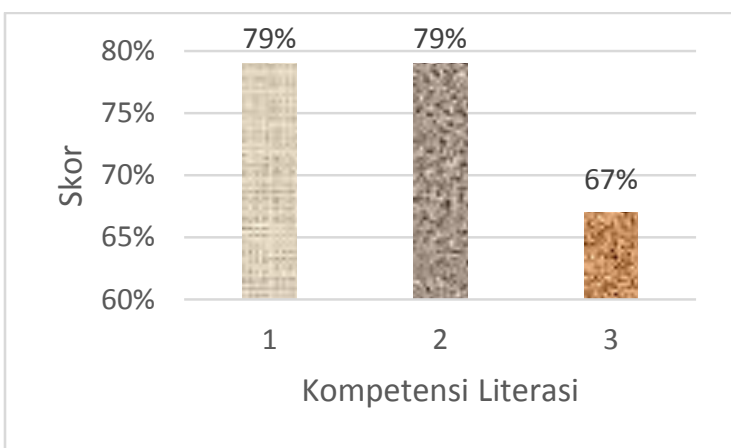

Gambar 1. Rerata Skor Kompetensi Literasi sains SMAN 1 Kendal

Keterangan:

1 : Menjelaskan fenomena ilmiah

2 : Mengevaluasi dan merancang penyelidikan ilmiah 3 : Menafsirkan data dan bukti ilmiah

Sedangkan pembagian level kompetensi literasi sains secara ringkas pembagian kriteria kompetensi literasi sains tersebut disajikan dalam Tabel 1.

Tabel 1. Level Kompetensi Literasi sains Siswa SMAN 1 Kendal

\begin{tabular}{llll}
\hline No & Level & \multicolumn{2}{l}{ Jumlah Siswa Tiap Kelas } \\
\cline { 3 - 4 } & Kompetensi & Ekperimen & Kontrol \\
\hline $\mathbf{1}$ & Tinggi & 27 & 16 \\
\hline $\mathbf{2}$ & Sedang & 8 & 19 \\
\hline $\mathbf{3}$ & Rendah & - & - \\
\hline
\end{tabular}

Secara keseluruhan berdasarkan Tabel 1, rerata skor kompetensi literasi sains siswa kelas eksperimen dan kontrol secara berturut-turut mendapat $72 \%$ dengan kategori tinggi dan $65 \%$ dengan kategori sedang.

Penelitian ini mengacu pada tingkat kognitif yang dapat dicapai siswa. Deskripsi penilaiannya sebagai berikut: 1) Level rendah, jika siswa hanya dapat menyelesaikan permasalahan dengan melaksanakan prosedur satu langkah, misalnya mengingat fakta, istilah prinsip, atau konsep menentukan satu titik informasi dari grafik atau tabel; 2) Level sedang, sedang jika siswa hanya dapat menyelesaikan soal yang berkaiatan dengan menggunakan dan menerapkan pengetahuan konseptual untuk menggambarkan atau menjelaskan fenomena, memilih prosedur tepat yang terdapat dua atau lebih tahapan dalam penyelesaian masalah, mengelola data, memprediksi atau mengolah data; dan 3) Level tinggi, jika siswa dapat menjawab soal literasi sains sampai tahap menganalisis fenomena atau data yang komprehensif, mensintesa atau mengevaluasi hasil, memberi dengan alasan yang tepat dari berbagai sumber, mengembangkan rencana untuk menyelesaikan masalah.

Berdasarkan pengujian hipotesis menggunakan Independent Sample T-test diperoleh nilai signifikasi memiliki nilai $-3,551$, sedangkan $t_{\text {tabeln }}$ na $-1,995$ Karena $t_{\text {hitung }}=-3,551<-1,995=$ $t_{\text {tabel}}$, maka $H_{o}$ ditolak $\left(H_{a}\right.$ diterima), sehingga ada perbedaan antara kelas yang menerapkan pembelajaran kimia berbasis etnosains dengan kelas yang tidak menerapkan pembelajaran kimia berbasis etnosains. Adapun nilai $\mathrm{N}$-gain pada kelas eksperimen sebesar 0,47 (kategori sedang) dan kelas kontrol sebesar 0,28 (kategori rendah). Ketercapaian kemampuan literasi sains secara keseluruhan diperoleh dengan menghitung rata-rata persentase siswa yang menjawab soal dengan benar pada tiap-tiap butir soal. Ketercapaian kompetensi literasi sains dikategorikan dalam tiga level yaitu level tinggi, sedang dan rendah.

Perolehan data hasil penelitian terkait literasi sains pada masing-masing kompetensi yang diperoleh melalui persentase ketercapaian hasil tes setiap indikator pada masing-masing kompetensi. Persentase yang diperoleh dari perbandingan nilai masing-masing siswa dengan nilai maksimal dan mencari nilai rerata ketercapaian kemampuan literasi sains pada setiap indikator pada aspek kompetensi literasi sains.

Perolehan skor terendah pada analisis butir soal dengan indikator mengidentifikasi asumsi, bukti dan penalaran dengan ilmu terkait. Sedangkan persentase tertinggi terdapat pada butir soal dengan indikator menjelaskan implikasi potensial dari penerapan pengetahuan sains bagi masyarakat. Soal kompetensi literasi sains pada umumnya memiliki tingkat kesulitan lebih tinggi sehingga siswa membutuhkan kemampuan analisis dan pemahaman konsep yang baik untuk dapat menyelesaikan tes kompetensi literasi sains. Peranan inkulturasi budaya dalam pembelajaran sains yaitu dengan merekonstruksi sains masyarakat ke dalam sains ilmiah dapat meningkatkan 
pengetahuan dan keterampilan siswa (Sudarmin, et $a l$, 2015). Hal ini diperkuat dengan penelitian Sumarni, et al, (2016) bahwa pembelajaran sains berbasis etnosains mampu mengembangkan kemampuan generik sains dan literasi sains.

Kemampuan literasi sains siswa tertinggi terdapat pada penelitian ini adalah pada aspek menjelaskan fenomena ilmiah yang kemudian disusul oleh aspek mengevaluasi dan merancang penyelidikan ilmiah dan aspek menafsirkan data dan bukti ilmiah. Aspek kompetensi menjelaskan fenomena ilmiah yang dicapai menunjukkan tentang kemampuan siswa untuk mengaplikasikan pengetahuan sains yang dipahami untuk memecahkan masalah pada soal literasi sains. Konsep pengetahuan siswa sangat berpengaruh pada kemampuan siswa untuk menjelaskan atau memprediksi fenomena ilmiah. Level tinggi yang didapatkan pada aspek menjelaskan fenomena ilmiah memberikan gambaran bahwa siswa mempunyai kemampuan yang cukup optimal untuk menjelaskan fenomena ilmiah yang didorong oleh faktor-faktor yang mempengaruhi kemampuan literasi sains.

Kompetensi mengevaluasi dan merancang penyelidikan ilmiah menunjukkan bahwa siswa mampu memahami topik dan ciri khas fenomena yang ada pada permasalahan literasi sains. Permasalahan pada butir soal literasi sains menuntut siswa menganalisis keterkaitan pengetahuan ilmiahnya dengan fenemona yang ada di masyarakat. Hal ini sesuai teori pembelajaran kognitif, bahwa pengetahuan awal siswa digunakan untuk mengolah informasi baru dengan mengaitkan informasi baru dengan pengetahun awal (Hartati, 2016). Kemampuan siswa mengidentifikasi isu ilmiah sangat dipengruhi oleh kualitas pengetahuan siswa.

Pencapaian menafsirkan data dan bukti ilmiah dapat dilihat dari kemampuan siswa mengartikan bukti ilmiah dan membuat kesimpulan melalui mengekplanasi hasil yang ada pada butir soal literasi sains (Fibonacci \& Sudarmin, 2014). Kemampuan siswa mengolah bukti ilmiah juga digambarkan dengan cara identifikasi hipotesis, hasil dan alasan dalam menarik kesimpulan terhadap pemecahan masalah terkait konsep materi (OECD, 2019).

Berdasarkan hasil peningkatan N-gain dengan kategori sedang ini dipengaruhi oleh faktor internal siswa yang belum terbiasa dalam mengerjakan tes literasi sains dan belum terbiasanya dalam mempelajari budaya kearifan lokal daerah dalam konteks kimia, sehingga siswa membutuhkan waktu yang lebih banyak dalam memahami kimia dalam konteks budaya daerah setampat. Faktor yang mempengaruhi kemampuan kompetensi literasi sains dalam penelitian ini, salah satunya adalah pendekatan pembelajaran yang digunakan pada proses pembelajaran. Pendekatan pembelajaran yang berbasis pada kehidupan masyarakat mampu membangun kompetensi literasi sains melalui keterampilan proses sains (Sofiana \& Wibowo, 2019). Salah satu model pembelajaran yang cocok untuk pembelajaran sains adalah pembelajaran kimia terintegrasi etnosains. Pembelajaran berbasis proyek (project based learning) merupakan salah satu model pembelajaran saintifik yang telah banyak diteliti dan ditengarai efektif dalam meningkatkan literasi sains (Afriana, et al, 2015) dan sikap terhadap sains (Tseng, et al, 2013). Pada pembelajaran kimia terintegrasi etnosains yang diajarkan tidak terlepas dari konteks sosial dan menitikberatkan pada penguasaan materi dalam mempersiapkan pengetahuan yang harus diketahui.

Pembelajaran kimia yang baik adalah pembelajaran kimia yang dapat membuat siswa memahami konsep-konsep kimia dalam penggunaan teori-teori kimia untuk menjelaskan fenomena alam, dapat menyelesaikan permasalahan dan mengambil keputusan berdasarkan konsepkonsep kimia yang telah diterimanya (Sumarni, 2018). Penelitian tentang literasi sains mempunyai ciri khas dimana materi-materi harus dikaitkan dengan contoh-contoh dalam kehidupan sehari-hari, dan mengkaitkan konsep kimia dengan informasi yang pernah didapatkan siswa melalui media cetak atau elektronik (Mann \& Treagust, 2010). Dalam penelitian ini digunakan fenomena budaya lokal daerah sebagai contoh materi dalam kehidupan sehari-hari seperti pembuatan batu bata, batik, es dawet sukun ireng serta momoh. Lingkungan 
sosial-budaya perlu mendapat perhatian serius dalam mengembangkan pendidikan sains/kimia karena didalamnya terpendam sains asli yang dapat berguna bagi kehidupan di masyarakat (Suastra, 2010).

Ketika mempunyai kemampuan literasi sains yang baik, maka siswa mampu mencari pengetahuan terkait kealamiahan alam semesta secara sistematis dengan metode ilmiah untuk menyelidiki, mengidentifikasi, mengasumsikan dan mengeksplorasi fenomena alam (Celik, 2014). Kemampuan literasi sains juga dipengaruhi oleh sikap sains (attitude towards science), terkait dengan emosi yang meliputi minat dan kenyamanan belajar sains (Hung, et al, 2012). Sehingga aspek kompetensi sains dan attitude towards science mempengaruhi pencapaian kemampuan kompetensi literasi sains siswa. Attitude towards science mampu membuat siswa tertarik pada topik ilmiah dan selanjutnya mendapatkan serta menerapkan pengetahuan sains dan teknologi untuk kemanfaatan pribadi, sosial, dan global (Pratiwi, 2019). Berdasarkan hasil penelitian tersebut bahwa pembelajaran kimia berbasis etnosains dapat digunakan dalam pembelajaran kimia untuk mengembangkan kemampuan literasi sains siswa. Pembelajaran kimia berbasis etnosains juga dapat dijadikan masukan pengambilan kebijakan dalam pengembangan kurikulum dan pembelajaran sains berdasarkan lingkungan sosial budaya masyarakat, sehingga secara jangka panjang mampu ikut serta sebagai langkah untuk meningkatkan kualitas pendidikan di Indonesia.

\section{PENUTUP}

Berdasarkan hasil penelitian tersebut dapat disimpulkan bahwa pembelajaran kimia berbasis etnosains dapat meningkatkan kemampuan literasi sains siswa. Hal ini dibuktikan melalui pengujian hipotesis menggunakan Independent Sample T-test diperoleh nilai signifikasi memiliki nilai $-3,551$, sedangkan $t_{\text {tabel }}$ nya $-1,995$ Karena $t_{\text {hitung }}=-3,551<$ $1,995=t_{\text {tabel}}$, maka $H_{o}$ ditolak $\left(H_{a}\right.$ diterima $)$, sehingga ada perbedaan antara kelas yang menerapkan pembelajaran kimia berbasis etnosains dengan kelas yang tidak menerapkan pembelajaran kimia berbasis etnosains. Adapun nilai N-gain pada kelas eksperimen sebesar 0,47 (kategori sedang) dan kelas kontrol sebesar 0,28 (kategori rendah).

\section{DAFTAR PUSTAKA}

Afriana, J., Permanasari, A., \& Fitriani, A. (2016). Project Based Learning Integrated To Stem To Enhance Elementary School's Students Scientific Literacy. Jurnal Pendidikan IPA Indonesia. 5(2): 261-267.

Celik, S. (2014). Chemical Literacy Levels of Science and Mathematics Teacher Candidates. Australian Journal of Teacher Education. 39(1): 1-15.

Chonkaew, P., Sukhummek, B., \& Faikhamta, C. (2016). Development of Analytical Thinking Ability and Attitudes Towards Science Learning of Grade-11 Students Through Science Technology Engineering and Mathematics (STEM Education) in The Study of Stoichiometry. Chemistry Education Research and Practice. 17(4): 842-861.

Fasasi, R. A. (2017). Effects of Ethnoscience Instruction, School Location, and Parental Educational Status on Learners' Attitude Towards Science. Journal International Journal of Science Education. 39(5): 548564.

Fibonacci, A., \& Sudarmin. (2014). Development Fun-Chem Learning Materials Integrated Socio-Science Issues to Increase Students Scientific Literacy. International Journal of Science and Research (IJSR). 3(11): 708713.

Hadi, W. P. \& Ahied, M. (2017). Kajian Etnosains Madura dalam Proses Produksi Garam sebagai Media Pembelajaran IPA Terpadu. Jurnal Ilmiah Rekayasa. 10(2): 79-86.

Handayani, G., Adisyahputra \& Indrayanti, R.. (2018). Hubungan Keterampilan Proses Sains Terintegrasi dan Kemampuan Membaca Pemahaman Terhadap Literasi Sains Pada Mahasiswa Calon Guru Biologi. Biosfer: Jurnal Pendidikan Biologi. 11(1): 21-31. 
Hartati, R. (2016). Peningkatan Aspek Sikap Literasi Sains Siswa SMP Melalui Penerapan Model Problem Based Learning Pada Pembelajaran IPA Terpadu. Edusains. 8(1): 90-97.

Hung, C. M., Hwang, G. J., \& Huang, I. (2012). A project-based digital storytelling approach for improving students' learning motivation, problem-solving competence and learning achievement. Journal of Educational Technology \& Society. 15(4): 368-379.

Kun, P. Z. (2013). Pembelajaran Sains Berbasis Kearifan Lokal. Prosiding: Seminar Nasional Fisika dan Pendidikan Fisika. 114.

Mann, M., \& Treagust, D. F. (2016). Students Conceptions About Energy and the Human Body. Science Education International. 2(13): 144-159.

McCright, A. M. (2012). Enhancing Students' Scientific and Quantitative Literacies Through an Inquiry-Based Learning Project on Climate Change. Journal of the Scholarship of Teaching and Learning. 12(4): 86-101.

Mussana. (2012). Artikulasi Pendidikan Guru Berbasis Kearifan Lokal untuk Mempersiapkan Guru yang Memiliki Kompetensi Budaya. Jurnal Pendidikan dan Kebudayaan. (18)3: 328-341.

Nieto, C., \& Ling, L.H. (2010). Cultural Competence: Its Influence on the Teaching and Learning of International Education. Jurnal of Studies in International Education. 14(4): 406-425.

OECD. (2019). PISA 2018 Results: What Students Know and Can Do. Volume 1. Paris: OECD Publishing.

Parmin, Sajidan, Ashadi, Sutikno, \& Fibriana, F. (2017). Science Integrated Learning Model to Enhance the Scientific Work Independence of Student Teacher in Indigenous Knowledge Transformation. Jurnal Pendidikan IPA Indonesia. 6(2): 365372.
Pratiwi, I. Efek Program PISA Terhadap Kurikulum di Indonesia. Jurnal Pendidikan dan Kebudayaan. 4(1): 51-71.

Redhana, I. W. (2018). No Title Mengembangkan Keterampilan Abad Ke-21 dalam Pembelajaran Kimia. Jurnal Inovasi Pendidikan Kimia. 13(1): 2239-2253.

Setiawan, B., Innatesari, D. K., Sabtiawan, W. B., \& Sudarmin, S. (2017). The Development of Local Wisdom-Based Natural Science Module to Improve Science Literation of Students. Jurnal Pendidikan IPA Indonesia. 6(1): 49-54.

Sofiana \& Wibowo, T.. (2019). Pengembangan Modul Kimia Socio-Scientific Issues (SSI) Materi Reaksi Reduksi Oksidasi. JEC: Journal of Educational Chemistry. 1(2): 92106.

Suardana, I. N., Liliasari \& Ismunandar. (2013). Peningkatan Penguasaan Konsep Mahapeserta Didik Melalui Praktikum Eletrolisis Berbasis Budaya Lokal. Jurnal Pendidikan dan Pembelajaran. 20(1): 45-52.

Suastra, I.W.. (2010). Model Pembelajaran Sains Berbasis Budaya Lokal untuk Mengembangkan Kompetensi Dasar Sains dan Nilai Kearifan Lokal di SMP. Jurnal Pendidikan dan Pengajaran. 43(2): 8-16.

Suastra, I.W.. (2013). Model Pembelajaran Fisika Untuk Mengembangkan Kreativitas Berpikir Dan Karakter Bangsa Berbasis Kearifan Lokal Bali. Jurnal Pendidikan Indonesia. 2(2): 223-233.

Sudarmin, Mastur, Z. \& Parmin. (2014). Merekontruksi Pengetahuan Sains Ilmiah Berbasis Budaya dan Kearifan Lokal di Kepulauan Karimunjawa Sebagai Wahana Menumbuhkan Soft Skill Konservasi. Jurnal Penelitian Pendidikan. 31(1): 55-61.

Sudarmin \& Pujiastuti, S. E. (2015). Scientific Knowledge Based Culture and Local Wisdom in Karimunjawa for Growing Soft Skills Conservation . International Journal of Science and Research (IJSR). 4(9): 23197064 
Sudarmin, Febu, R., Nuswowati, M.. \& Sumarni, W.. (2017). Development of Ethnoscience Approach in The Module Theme Substance Additives to Improve the Cognitive Learning Outcome and Student's entrepreneurship. Journal of Physics Conference Series. 824(1): 012024.

Sumarni, W, Sudarmin, Wiyanto \& Supartono. (2016). The Reconstruction of Society Indigenous Science into Scientific Knowledge in the Production Process of Palm Sugar. Journal of Turkish Science Education. 13(4): 281-292.

Sumarni, W., Rusilowati, A., \& Susilaningsih, E. (2017). Chemical Literacy of Teaching Candidates Studying The Integrated Food Chemistry Ethnosciences Course. Journal of Turkish Science Education. 14(3): 40-72

Sumarni, W. (2018). Pembelajaran Kimia Dalam Kehidupan Bebasis Proyek Terintegrasi
Etnosains Bagi Mahapeserta Didik Calon Guru. Disertasi. Semarang: Universitas Negeri Semarang.

Turiman P., Omar J., Daud A M., \& Osman K. (2012). Fostering the 21st Century Skills Through Scientific Literacy and Science Process Skills. Procedia - Social and Behavioral Sciences . 59: 110-116.

Toharudin, U. Hendrawati, S. \& Rustaman, A. (2011). Membangun Literasi Sains Peserta Didik. Bandung: Humaniora.

Tseng, K.H., Chang, C., Lou, S.J, \& Chen, W.P. (2013). Attitudes Towards Science, Technology, Engineering and Mathematics (STEM) in a Project-Based Learning (PjBL) Environment. International Journal of Technology and Design Education. Int $J$ Technol Des Educ. 23(1):87-102. 